\title{
An experimental and kinetic modeling study on the oxidation of 1,3-dioxolane
}

\author{
Alina Wildenberg ${ }^{1}$, Yann Fenard ${ }^{1, *}$, Maxime Carbonnier ${ }^{2,3,4}$, Alan Kéromnès ${ }^{4}$, Benoîte Lefort ${ }^{4}$, Zeynep \\ Serinyel $^{2,3}$, Guillaume Dayma ${ }^{2,3}$, Luis Le Moyne ${ }^{4}$, Philippe Dagaut ${ }^{2}$, Karl Alexander Heufer ${ }^{1}$ \\ ${ }^{1}$ Physico Chemical Fundamentals of Combustion, RWTH Aachen University, 52056 Aachen, Germany \\ ${ }^{2}$ CNRS-INSIS, Institut de Combustion, Aérothermique, Réactivité et Environnement, 1C Avenue de la \\ Recherche Scientifique, 45071 Orléans cedex 2, France \\ ${ }^{3}$ Université d'Orléans, 6 Avenue du Parc Floral, 45100 Orléans, France \\ ${ }^{4}$ DRIVE EA1859, Université de Bourgogne Franche-Comté, 49 rue Mademoiselle Bourgeois, 58027 Nevers, \\ France
}

\section{*yann.fenard@pcfc.rwth-aachen.de}

\begin{abstract}
The modern catalytic or enzymatic advances allow the production of novel biofuel. Among them, 1,3dioxolane can be produced from formaldehyde and ethylene glycol, both can be obtained from biomass. In this study, the oxidation of 1,3-dioxolane is studied at stoichiometric conditions. The ignition delay times of 1,3-dioxolane $/ \mathrm{O}_{2} /$ inert mixtures were measured in a shock tube and in a rapid compression machine at pressures of 20 to 40 bar and temperatures ranging from 630 to $1300 \mathrm{~K}$. The pressure profiles recorded in the rapid compression machine show a first stage of ignition enlightening the influence of the low temperature chemistry of combustion. Furthermore, mole fraction profiles of the stable intermediates produced during the oxidation of 1,3-dioxolane were measured in a jet-stirred reactor at 10 bar. Following these observations, a detailed kinetic model was developed with reaction rate coefficients and thermochemical data calculated by theoretical calculations or estimated by analogies to suitable molecules. In order to get an insight into the most important reaction pathways brute force sensitivity analysis and reaction pathway analysis were performed with the proposed model and discussed. It became clear that in the fuel-in-air case for the alkylhydroperoxide of 1,3-dioxolane the ring opening betascission pathway is favored against the further alkane-like second addition to molecular oxygen, what leads to a limited negative temperature coefficient.
\end{abstract}




\section{Introduction}

Humanity faces climate change. To address this problem a promising approach is to replace fossil fuels by biofuels obtained by second generation biomass. Within the cluster of excellence Fuel Science Center (FSC) [1] 1,3-dioxolane (structure see Fig. 1) was identified as a promising biofuel as its reactants ethylene glycol and formaldehyde can be yielded from biomass [2-5]. Currently, the FSC is working on a catalytic pathway to produce dioxolane from $\mathrm{CO}_{2}$ and ethylene glycol. Furthermore, 1,3-dioxolane has already shown soot reducing properties as a diesel additive [6]. To examine the capability of 1,3-dioxolane to be used as a biofuel its kinetics must be investigated under engine relevant conditions. So far the kinetics of the oxidation of 1,3-dioxolane by $\dot{\mathrm{OH}}$ radicals was studied under atmospheric conditions by Sauer et al. [7]. It was observed that the two possible radicals, 1,3-dioxolan-2-yl and 1,3-dioxolan-4-yl, are formed in equal amounts and then are reacting quickly with $\mathrm{O}_{2}$ to form peroxyl radicals indicating a possible low temperature chemistry of combustion. Cutler et al. [8] studied the pyrolysis of 1,3-dioxolane in steam at atmospheric pressures. Under these conditions they also observed the formation of two possible radicals but with the radical at the ethylene side being formed twice as much as the other radical at the methylene side (structure see Fig. 1). The authors concluded that this branching is due to the fact that the ethylene position has twice as many hydrogen atoms than the oxymethylene side. Cutler et al. further showed, that the main products of the pyrolysis are $\mathrm{H}_{2}, \mathrm{CO}, \mathrm{CO}_{2}$, methane, ethane and ethylene [8]. The thermal decomposition of 1,3-dioxolane was examined by FernándezSánchez et al. [9] and Guenther et al. [10] at 373-575 K and 455-525 K, respectively, and the photodecomposition was examined by B. C. Roquitte [11]. All three examined that dioxolane mainly reacts to the pyrolysis products observed by Cutler et al. [8]. The gas phase oxidation of 1,3-dioxolane under atmospheric pressure was examined by Molera et al. [12]. They also observed that 1,3-dioxolane reacts to two different radicals, whereby the radical at the energetically unfavorable ethylene side is formed more because it is statistically more likely. However, these studies do not address the combustion of 1,3-dioxolane under engine relevant conditions.

In this work a detailed kinetic model for the oxidation of 1,3-dioxolane is developed and validated against ignition delay times (IDT) and mole fraction profiles of the stable oxidation intermediates of dioxolane obtained in a jet stirred reactor (JSR). The model is used to get a deeper insight in the oxidation of dioxolane through sensitivity and reaction pathway analysis.

\section{Experimental}

The ignition delay time measurements were performed in a high pressure shock tube (ST) and in a rapid compression machine (RCM) for stoichiometric conditions at 20 and 40 bar. The ST in DRIVE, used to measure IDTs at high temperatures, was previously described in [13]. It consists of a $4 \mathrm{~m}$-long driver section and a $5 \mathrm{~m}$ long driven section, divided by a double diaphragm, and connected to the mixture preparation tanks by a manifold. To avoid fuel condensation, the complete system is heated up to $60^{\circ} \mathrm{C}$. In the ST the IDT is defined as the time interval between the arrival of the reflected shock at the end wall and the ignition event, defined as the maximum slope of the pressure increase. To detect the position of the shock wave and its velocity, four piezoelectric pressure transducers (РCB 113B22) are installed in the driven section. The impact of the shock wave and the ignition event are detected by a pressure transducer (Kistler 603B1) at the endwall. The temperature behind the reflected shock wave $\left(T_{5}\right)$ was calculated with the help of the chemical equilibrium software Gaseq [14]. Uncertainties in reflected shock temperatures are estimated to $\pm 1 \%$ ( $\pm 10-15 \mathrm{~K})$ [13]. For both pressures a mixture with $2 \%$ fuel was prepared using a diluent $/ \mathrm{O}_{2}$ ratio of 13 with argon as bath gas. The used gases had a purity higher than $99.995 \%$ and 1,3-dioxolane, purchased from Sigma Aldrich, had a purity of $99.8 \%$. Intermediate and low temperature conditions were measured in the RCM at PCFC, RWTH Aachen University, which was previously described in [15]. It consists of a reaction chamber, a hydraulic section and a pneumatically driven piston and is connected by a manifold to the mixture preparation vessel. The reaction chamber is equipped with a dynamic pressure sensor (Kistler 6125C-U20) in order to measure the pressure during the experiment. Uncertainties are estimated to \pm 0.15 bar and $\pm 5 \mathrm{~K}$ on the compressed conditions [16]. The RCM used in this study is equipped with an adjustable endwall in order to vary the compression ratio. In the RCM the IDT is defined as the time between the end of compression and the ignition of the fuel, defined 
as the maximum increase in pressure. Measurements in the RCM were done in diluted conditions with a diluent ratio of 7.52 using argon 4.6 and nitrogen 5.0 as bath bas and oxygen 5.0, all purchased from Westfalen. 1,3-Dioxolane was purchased from Sigma-Aldrich with a purity of $99.8 \%$. Measurements in non-diluted conditions were not possible as the ignition delay times were getting shorter than $2 \mathrm{~ms}$, the lower limit measurable in the RCM.

Experiments were also performed in a fused silica jet-stirred reactor (JSR) already described in details and used in previous studies [17]. The reactor itself is surrounded by a regulated electrical oven and can be heated up to $1250 \mathrm{~K}$. It is located inside a pressure-resistant jacket, allowing the pressure to rise up to $10 \mathrm{~atm}$. The liquid fuel (CAS 4362-13-4, 99.8\% purity from Sigma Aldrich) was atomized by a nitrogen flow and vaporized in a heated chamber. The fuel $+\mathrm{N}_{2}$ mixture is carried to the reactor by a heated quartz capillary. The oxidizing stream $\left(\mathrm{O}_{2}+\mathrm{N}_{2}\right)$ flowed separately to avoid oxidation before reaching the 4 injectors providing stirring. Gaseous flowrates are regulated by thermal mass flow controllers (Brooks 5850E) whereas the liquid fuel is injected by an HPLC pump (Shimadzu LC10 AD VP) with an online degasser (Shimadzu DGU-20 A3). A low-pressure sonic probe was used to freeze the reactions and take samples for online and off-line analyses. Samples were analyzed online by FTIR or stored at low-pressure for offline GC analysis. The carbon balance was checked after each experiment and was found to be within $\pm 10 \%$. Uncertainties on the species mole fractions are due to several factors described in [18] and are estimated to be around $\pm 15 \%$. All experiments were performed at $10 \mathrm{~atm}$ between 700 and $1180 \mathrm{~K}$ after checking at that no low-temperature reactivity was observed between 500 and $700 \mathrm{~K}$.

\section{Theoretical calculations}

The thermochemical data of some species, important to model the oxidation of 1,3-dioxolane, were calculated. Species calculated are the 1,3-dioxolan $(\mathrm{RH})$ and the two radicals 1,3-dioxolan-2-yl and 1,3dioxolan-4-yl ( $\dot{R} 2$ and $\dot{R} 4)$, the $\beta$-scission products of the radicals 1,3-dioxolan-2-yl and 1,3-dioxolan-4-yl, $(\mathrm{O}=\mathrm{CCOC}, \mathrm{C}=\mathrm{COCO}$ and $\mathrm{O}=\mathrm{COC} \dot{\mathrm{C}})$ and the dioxolanyl peroxyl radicals $\left(\mathrm{R}_{2} \dot{\mathrm{O}}_{2}\right.$ and $\left.\mathrm{R} 4 \dot{O}_{2}\right)$. The thermodynamic data of the peroxyl radicals are particularly important as the addition to oxygen $\dot{R}+\mathrm{O}_{2} \rightleftharpoons \mathrm{RO}_{2}$ relies on the thermodynamic data of the reactants and products. Moreover, the reaction rate coefficients of the $\beta$-scission reactions of the radicals 1,3-dioxolan-2-yl and 1,3-dioxolan-4-yl were calculated. The geometries, frequencies and one dimensional hindered rotors were calculated with 10 degree resolution using the method B3LYP/6$31 \mathrm{G}(2 \mathrm{df}, \mathrm{p})$. The $\mathrm{G} 4$ combined method implemented in Gaussian 09 [19] using the atomization model was employed to calculate the standard heat of formation as recommended by Somers and Simmie [20]. Comparing the calculated standard heat of formation for 1,3-dioxolane of $71.08 \mathrm{kcal} / \mathrm{mol}$ to the measured one of $72.10 \mathrm{kcal} / \mathrm{mol}$ [21] only a small deviation is visible justifying the usage of the mentioned method. The method B3LYP/6-31G(2df,p) was used for the statistical thermodynamic. The thermodynamic properties were calculated with the python package TAMkin, detailed by Burke et al. [22]. Other thermodynamic data of species, specific to the submechanism of 1,3-dioxolane, were estimated with RMG. The standard heat of formation was calculated from the enthalpies calculated with the G4 method. The MESS software was used [23] to calculate the reaction rate parameters of the ring opening reactions of the radicals 1,3-dioxolan-2-yl and 1,3-dioxolan-4-yl. Rotational enantiomers where included when necessary. The collisional energy transfer was modeled with nitrogen as bath gas via $\left\langle\Delta E_{\text {down }}\right\rangle=200 \mathrm{~cm}^{-1} \cdot(T / 300 \mathrm{~K})^{0.85}$, where commonly chosen parameters were used [24]. The Lennard-Jones parameters for nitrogen $\sigma=3.681 \AA$ and $\varepsilon=67.89 \mathrm{~cm}^{-1}$ were used as recommended by Xu et al. [25]. The Lennard-Jones parameters for the dioxolanyl radicals were taken from the RMG database [26]. The reaction rate coefficients were calculated using the zero-curvature Eckart tunneling and then fitted with the modified Arrhenius equation $k(T)=A \cdot T^{n} \cdot \exp \left(\frac{E_{a}}{R T}\right)$ within a temperature range from 500 to $2200 \mathrm{~K}$. The pressure dependence was calculated for all computed reactions. For the $\beta$ scission of 1,3-dioxolane-2-yl the degeneracy was taken into account by multiplying the $A$-factor by 2 . The rates are plotted in the supplemental material (Fig.S.5-7).

The enthalpies at $0 \mathrm{~K}$ were obtained from the $\mathrm{G} 4$ combined method and used to calculate the bond dissociation energies of all $\mathrm{C}-\mathrm{H}$ bonds, $\mathrm{C}-\mathrm{O}$-bond and the $\mathrm{C}-\mathrm{C}$ bond of 1,3-dioxolane. The enthalpy of dioxolane was subtracted from the enthalpies of the resulting radicals after the dissociation of the bond. The bond 
dissociation energies of the $\mathrm{C}-\mathrm{H}$-bond at the methylene side of the 1,3-dioxolane is $1.8 \mathrm{kcal} / \mathrm{mol}$ lower compared to the similar pattern found in dimethoxymethane (DMM) [27]. The O-C-O bond angle in 1,3dioxolane is $120^{\circ}$ same as the corresponding dioxolanyl radical. Therefore, it does not need to rearrange when forming the radical. In contrast, the $\mathrm{O}-\mathrm{C}-\mathrm{O}$ angle changes from $109^{\circ}$ to $120^{\circ}$ for a linear structure when forming a radical, explaining the lower $\mathrm{BDE}$ of dioxolane compared to DMM. Also, the C-O-bond dissociation energy of dioxolane is lower than for DMM and can be attributed to the ring strain in dioxolane. As shown in Fig. 1, the $\mathrm{C}-\mathrm{H}$-bond of the ethylene group has a very similar bond dissociation energy to tetrahydrofuran (THF) [28], which is also a five member ring. In addition, Fig. 1 shows the numbering system used in this paper for naming the species in the model. The carbon atom of the methylene site is referred to as carbon 2. The dioxolanyl radical with the radical side at this position is therefore called 1,3-dioxolan-2-yl (Rं2). The species Q $400 \mathrm{OH}$ for example has a radical on carbon 4 and a hydroperoxyl group on carbon 5 .
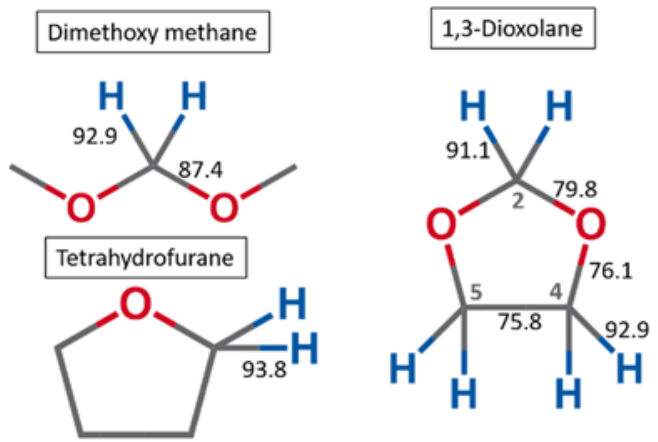

Fig. 1: Calculated bond dissociation energies for 1,3-dioxolane compared to bond dissociation energies from tetrahydrofuran and dimethoxy methane given in $\mathrm{kcal} / \mathrm{mol}$ shown in black. The numbering of carbon atoms is shown in grey, respectively.

\section{Kinetic modeling}

The model development in this work is based upon AramcoMech 3.0 [29] as base mechanism. The reaction classes for 1,3-dioxolane are derived from the work of Curran et al. [30].

For the unimolecular decomposition reactions analogies to a five membered cyclic ether [31] are assumed. The rate parameters for $\mathrm{H}$-atom abstraction reaction by $\dot{\mathrm{H}}, \dot{\mathrm{C}} \mathrm{H}_{3}$ and $\dot{\mathrm{C}}_{2} \mathrm{H}_{5}$ radicals were chosen similar to the case of diethoxy methylene [32]. The rate parameters for $\mathrm{H}$-atom abstraction reactions by $\mathrm{OH}$ radical were deduced from the work of Dagaut et al. [33] on 1,4-dioxane. The reaction rate constants for 1,3-dioxolane + $\mathrm{HO}_{2} \rightleftharpoons 1,3-$ dioxolan-2-yl $+\mathrm{H}_{2} \mathrm{O}_{2}$ are taken similar as in the case of dimethoxy methylene divided by a factor of two and for 1,3-dioxolane $+\mathrm{HO}_{2} \rightleftharpoons 1,3$-dioxolan-4-yl $+\mathrm{H}_{2} \mathrm{O}_{2}$, the rate parameters from di ethyl ether calculated by Mendes et al. [34] were used. The $\mathrm{H}$-atom abstraction by $\mathrm{CH}_{3} \mathrm{O}_{2}$ is treated as for $\mathrm{HO}_{2}$, however reduced by a factor of 1.5 to take into account the stabilization effect [30]. The rate parameters for the ring opening reactions of the radicals 1,3-dioxolan-2-yl and 1,3-dioxolane-4-yl calculated in this work are added to the model and also used to describe the $\beta$-scission reactions of the $\mathrm{QOOH}$ radicals, with an activation energy reduced by $2 \mathrm{kcal} / \mathrm{mol}$ to take into account the influence of the hydroperoxyl group.

In all other reaction classes, the reactions concerning carbon in position 2 of 1,3-dioxolane (Fig. 1) were treated as for the methylene carbon of dimethoxy methane. Despite Fig. 1 showing a difference of $1.8 \mathrm{kcal} / \mathrm{mol}$ between the BDE of 1,3-dioxolane and DMM this difference was not considered for the reaction rates deduced from DMM as the Evans-Polanyi plot for different similar molecule showed no clear trend (Fig.S.1).

For the carbon in position 4 and 5 (Fig. 1) the reaction parameters were determined in analogy to the rate coefficients of $\mathrm{H}$-atom separation on the primary radical position of dimethoxy methane [35]. The rates from dimethoxy methane were corrected, applying the ratio between secondary and primary position in alkane systems [36], therefore correspond to diethoxy methane, which is directly comparable to dioxolane. The reaction classes concerned are the bimolecular initiations, the $\mathrm{H}$-atom abstraction by $\mathrm{O}$ and $\mathrm{CH}_{3} \mathrm{O}$, the additions of radicals 1,3-dioxolan-2-yl and 1,3-dioxolan-4-yl on $\mathrm{O}_{2}$, the internal $\mathrm{H}$-atom migration $\mathrm{RO}_{2} \rightleftharpoons$ $\dot{\mathrm{QOOH}}$, the concerted elimination $\mathrm{RO}_{2} \rightleftharpoons$ unsaturated counterpart $+\mathrm{HO}_{2}$, the $\mathrm{HO}_{2}$ elimination from $\mathrm{QOOH}$, the 
cyclic ether formation, the ketohydroperoxide $(\mathrm{KHP})$ formation $\mathrm{OOOQOOH} \rightleftharpoons \mathrm{KHP}+\dot{\mathrm{OH}}$ and the decomposition of the KHP to products and a hydroxyl radical.

It is worth mentioning that only the formation of the bi-cyclic species 4,5-epoxy-1,3-dioxolane is considered as 4-hydroperoxy-1,3-dioxolan-5-yl is expected to behave similar to alkanes. 2-hydroperoxy-1,3-dioxolan-4-yl and 4-hydroperoxy-1,3-dioxolan-2-yl are expected to behave like THF [28] where no cyclic ether formation was observed as this reaction cannot compete with the other branching reactions of the hydroperoxy species $\dot{\mathrm{QOOH}}$. Overall, the $\beta$-scission reaction of the $\mathrm{QOOH}$ radical is widely favored. The detailed kinetic model and the thermodynamic data are given in the supplementary materials.

\section{Results and discussion}

\subsection{Ignition delay times}

Figure 2 presents the measured and simulated ignition delay times. For the simulations of the ignition delay times the kinetic solver Cantera was used [37]. In shock tube conditions constant volume simulations were performed. For the RCM experiments the heat loss was considered using effective volume profiles [38]. The ignition delay times simulated with the kinetic model lay within the uncertainty of the experimentally measured values. At high temperatures, IDTs measured in the ST show an Arrhenius behavior. At low to intermediate temperatures, IDTs show a weak negative temperature coefficient behavior, which is more pronounced at 40 bar than at 20 bar as commonly observed for alkanes for instance.

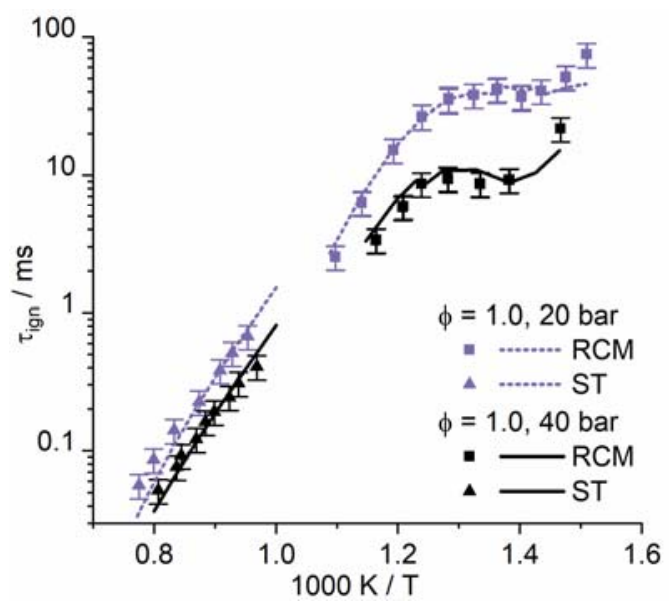

Fig. 2: Simulated (lines) and measured (symbols) ignition delay times for 20 and 40 bar for $\phi=1.0$. The ST measurements were carried out for $2 \mathrm{~mol}-\%$ fuel with a dilution $\mathrm{Ar} / \mathrm{O}_{2}$ of 13 . The RCM experiments were performed for a dilution inert gas $/ \mathrm{O}_{2}$ of 7.52.

In order to have a deeper insight into the reaction pathways influencing the ignition delay times the most, a brute force sensitivity analysis was performed at 20 bar and an equivalence ratio of 1.0 for $1200 \mathrm{~K}$ at ST conditions and at $710 \mathrm{~K}$ at RCM conditions (Fig. 3).

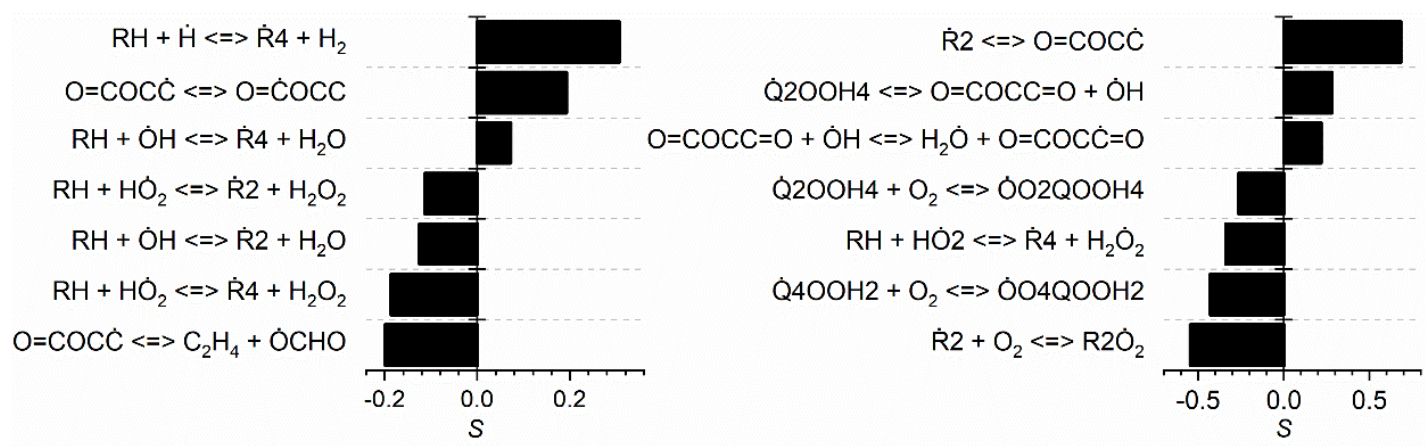

Fig. 3: Brute force sensitivity analysis at $\phi=1.0$ and 20 bar for ST conditions at $1200 \mathrm{~K}$ (left) and for RCM conditions at $710 \mathrm{~K}$ (right). 
The sensitivity coefficients are defined as $S=\log \left(\tau_{i}^{+} / \tau_{i}^{-}\right) / \log (2.0 / 0.5)$ with $\tau_{i}^{+}$being the ignition delay time computed with the reaction rate constant $k_{i}$ multiplied by a factor of two and $\tau_{i}^{-}$the ignition delay time corresponding to $k_{i}$ divided by 2 . If a reaction is denoted with a positive sensitivity coefficient, an increase in the rate of this reaction leads to an increase in the IDTs (i.e. decrease in reactivity) and a negative coefficient depicts a decrease in the ignition delay time (i.e increase in reactivity). The sensitivity analysis shows for both temperatures that the $\mathrm{H}$-atom abstraction by $\dot{\mathrm{OH}}$ and $\mathrm{HO}_{2}$ forming 1,3-dioxolan-2-yl and the $\mathrm{H}$-atom abstraction by $\mathrm{HO}_{2}$ forming 1,3-dioxolan-4-yl increase the reactivity as they consume the 1,3-dioxolane the most. Additionally, $\mathrm{HO}_{2}$ is reacting to produce hydrogen peroxide at $710 \mathrm{~K}$ that can undergo an $\mathrm{O}-\mathrm{O}$ bond dissociation with increasing temperature giving two $\dot{O H}$ radicals that react with the fuel which ultimately triggers the ignition. At $1200 \mathrm{~K}$ the hydrogen peroxide immediately decomposes into two $\mathrm{OH}$ radicals promoting the reactivity by chain branching reaction. The formation of 1,3 -dioxolan-4-yl by $\mathrm{H}$-atom abstraction by an $\dot{\mathrm{OH}}$ radical decreases reactivity, because it consumes a very reactive $\dot{\mathrm{OH}}$ radical while the decomposition of 1,3-dioxolan-4-yl does not produce reactive radicals. The decomposition of 1,3-dioxolan-2yl meanwhile gives OCHO that reacts to yield $\dot{\mathrm{H}}$ and $\mathrm{CO}_{2}$ with $\dot{\mathrm{H}}$ being a chain branching agent. The $\mathrm{H}$-atom abstraction by $\dot{H}$ at both sides decreases the reactivity at high temperatures. At high temperatures the $\dot{H}$ is responsible for the chain branching reaction $\dot{\mathrm{H}}+\mathrm{O}_{2} \rightleftharpoons \dot{\mathrm{O}}+\dot{\mathrm{OH}}$ increasing reactivity as it forms two active radicals. When reacting with 1,3-dioxolane at high temperature, the $\mathrm{H}$ radical is not available for this chain branching reaction anymore and thereby decreases the overall reactivity although it consumes the 1,3dioxolane. In ST conditions ( $1000 \mathrm{~K}$ to $1300 \mathrm{~K}$ ) the $\beta$-scission reaction forming $\mathrm{C}_{2} \mathrm{H}_{4}$ and OCHO is increasing the reactivity while the isomerization from ethyl-2yl formate $(\mathrm{O}=\mathrm{COC} \dot{\mathrm{C}})$ to ethyl formyl $(\mathrm{O}=\dot{\mathrm{C} O C C})$ has the opposite effect. The decomposition of OCHO gives $\mathrm{CO}_{2}$ and a $\mathrm{H}$ while ethyl formyl decomposes to $\mathrm{CO}$ or $\mathrm{CO}$, which are stable and unreactive, and $\dot{\mathrm{C}}_{2} \mathrm{H}_{5}$ or $\mathrm{C}_{2} \mathrm{H}_{5} \mathrm{O}$ that are less reactive than a hydrogen radical, which is responsible for the chain branching reaction with $\mathrm{O}_{2}$. At a lower temperatures of $720 \mathrm{~K}$ the most sensitive reaction on the IDTs increasing reactivity is the addition of 1,3-dioxolan-2-yl to $\mathrm{O}_{2}$ as it is the first step leading to the low temperature chain branching process [39]. The reaction competing with this low temperature chain branching is the ring opening reaction of 1,3-dioxolan-2-yl to ethyl format-5-yl $(O=C O C \dot{C})$ which, consequently, decreases the reactivity. The $\beta$-scission of the radical 4-hydroperoxy-1,3-dioxolan-2-yl (Q2OOH4) forming the stable intermediate 2-oxoethyl formate $(\mathrm{O}=\mathrm{COCC}=\mathrm{O})$ is decreasing reactivity as it also stands in competition to low temperature branching. In order to investigate the pathways consuming the 1,3-dioxolane in the low temperature region a reaction pathway analysis was done at $720 \mathrm{~K}$ for 20 bar and an equivalence ratio of 1.0 (Fig. 4 and Fig. 5).

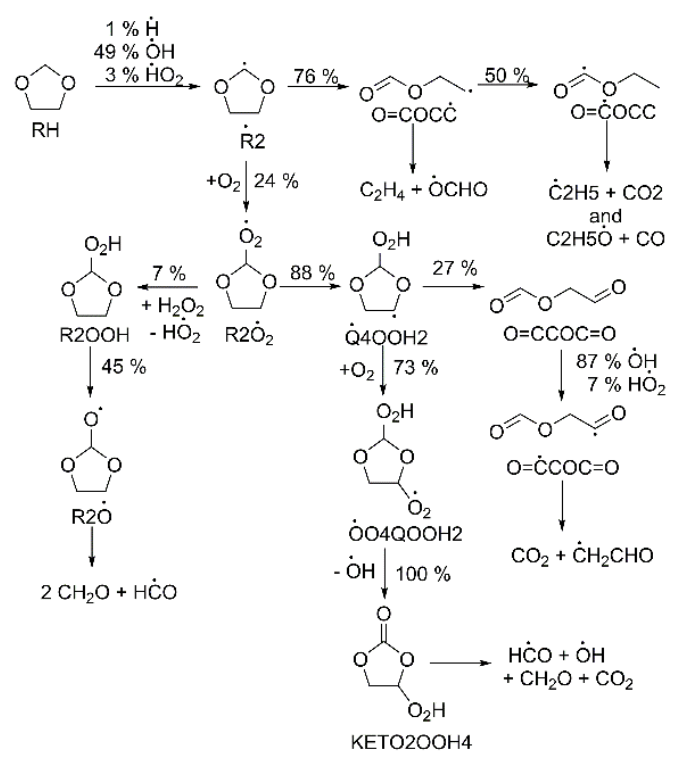

Fig. 4: Reaction pathway analysis at $720 \mathrm{~K}, 20$ bar and $\phi=1.0$ performed in a constant volume ideal gas reactor for the radical $1,3-$ dioxolan-2-yl (Rं2) with a diluent $/ \mathrm{O}_{2}$ ratio of 7.52 at $10 \%$ fuel consumption. 


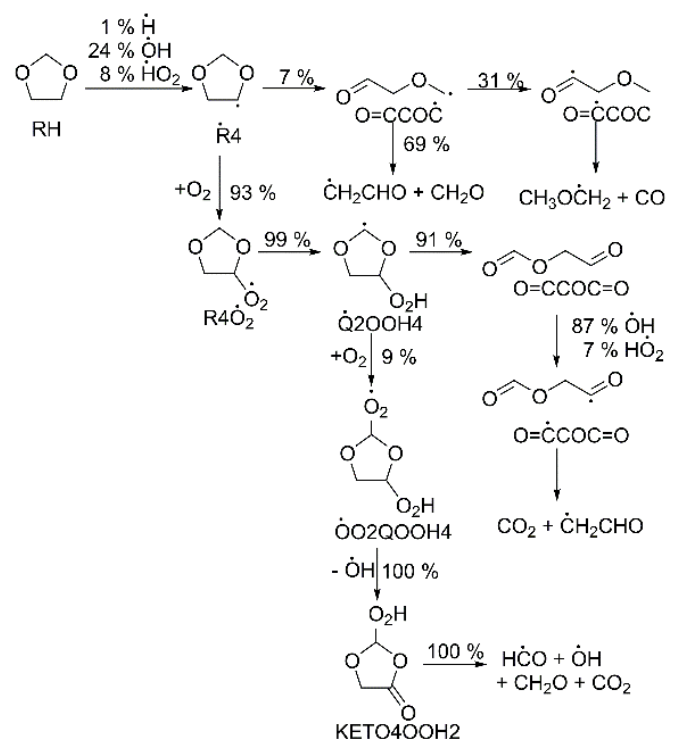

Fig. 5: Reaction pathway analysis at $720 \mathrm{~K}, 20$ bar and $\phi=1.0$ performed in a constant volume ideal gas reactor for the radical $1,3-$ dioxolan-4-yl (Rं4) with a diluent/ $\mathrm{O}_{2}$ ratio of 7.52 at $10 \%$ fuel consumption.

The reaction pathway analysis shows that the 1,3-dioxolan-2-yl radical is formed faster than the 1,3-dioxolan4-yl radical. It is attributed to the lower bond dissociation energy of the $\mathrm{C}-\mathrm{H}$ bond at the methylene side compared to the $\mathrm{C}-\mathrm{H}$ bond at the ethylene side. Under these conditions the ratio is roughly $3 / 2$ in favor of 1,3dioxolan-2-yl. The 1,3-dioxolan-4-yl radical then mainly reacts via addition to $\mathrm{O}_{2}$ forming the peroxyl radical 4peroxly-2,4-dioxolane $\left(\mathrm{R}_{4} \dot{\mathrm{O}}_{2}\right)$ while the 1,3-dioxolan-2-yl radical mainly decomposes via $\beta$-scission (ring opening reaction) instead of following the low temperature chain branching pathway. The reaction enthalpy for the $\beta$-scission of 1,3-dioxoalen-4-yl is positive and can therefore not compete against the addition to $\mathrm{O}_{2}$. The $\beta$-scission of 1,3-dioxoalen-2-yl is, as the addition to $\mathrm{O}_{2}$, an exothermic reaction and takes place quickly (Fig.S.2). As the branching is determined by the unimolecular reaction the addition to $\mathrm{O}_{2}$ is suppressed nearly entirely. This observation also stands for the $\mathrm{QOOH}$ species for the second addition to $\mathrm{O}_{2}$. The 4-hydroperoxy-

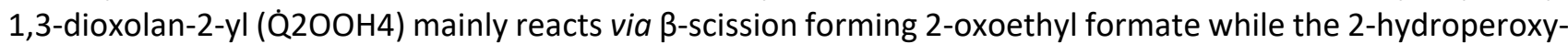
1,3-dioxolan-4-yl ( $\left.\mathbf{Q}^{4} \mathrm{OOH} 2\right)$ mainly reacts by addition to $\mathrm{O}_{2}$. The $\beta$-scission of $\mathrm{QOOH}$ species shows a negligible effect in the low temperature chemistry of linear alkanes [40]. However, this class of reaction is sensitive on the reactivity in the case of 1,3-dioxolane the same way it was observed for tetrahydrofuran [28]. The reaction pathway analysis for 1,3-dioxolan-4-yl shows that 4-peroxly-1,3-dioxolane $\left(R 4 \dot{O}_{2}\right)$ only isomerizes to 4hydroperoxy-1,3-dioxolan-2-yl( $\mathbf{Q} 2 \mathrm{OOH} 4)$ as a 6-membered transition in the $\mathrm{H}$-atom migration is favored compared to a 5-membered transition due to lower ring-strain.

The reaction pathway analysis shows that the two oxygen in the ring structure impede the addition to $\mathrm{O}_{2}$ if both oxygens are in $\alpha$ position to the radical position. In this case also the equilibrium of the $\mathrm{QOOH}$ species of dioxolane is shifted to the $\beta$-scission reaction and not to the olefin formation as for alkanes.

\subsection{Mole fraction profiles}

Figure 6 presents the measured and simulated mole fraction profiles of stable intermediates produced during the oxidation of 1,3-dioxolane for an equivalence ratio of $\phi=1.0$. The JSR simulations were performed with Cantera under the assumption of a perfectly stirred reactor. 

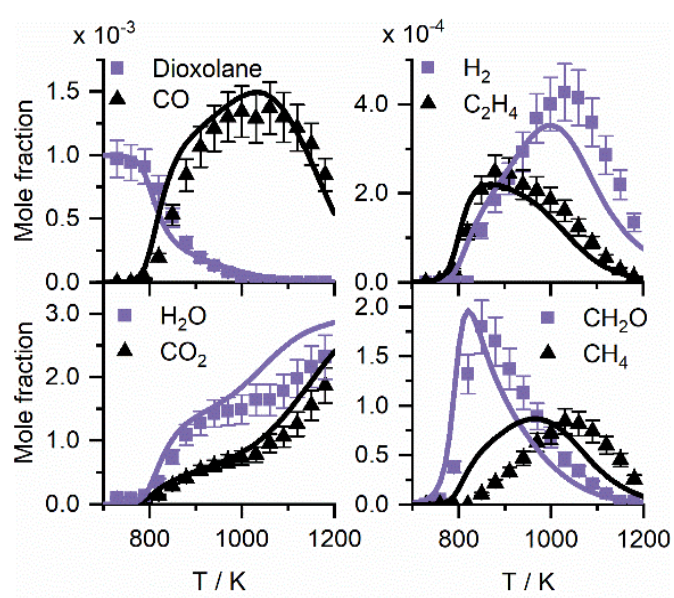

Fig. 6: Simulated (lines) and experimental (symbols) mole fraction profiles for the oxidation of 1,3-dioxolane $/ \mathrm{O}_{2} / \mathrm{N}_{2}$ mixtures in a JSR at $10 \mathrm{~atm}$ for $\phi=1.0$ and $\tau=700 \mathrm{~ms}$.

The most abundant species are the 1,3-dioxolane itself, carbon monoxide, formaldehyde, methane, hydrogen, ethylene, carbon dioxide and water. Ethane and acetaldehyde were detected in low amounts. All these species are formed through the high temperature reaction pathways. No specific low temperature species of 1,3dioxolane were observed during the JSR experiments. As an illustration a reaction pathway analysis was performed at $10 \mathrm{bar}$ and $850 \mathrm{~K}$ (Fig. 7).

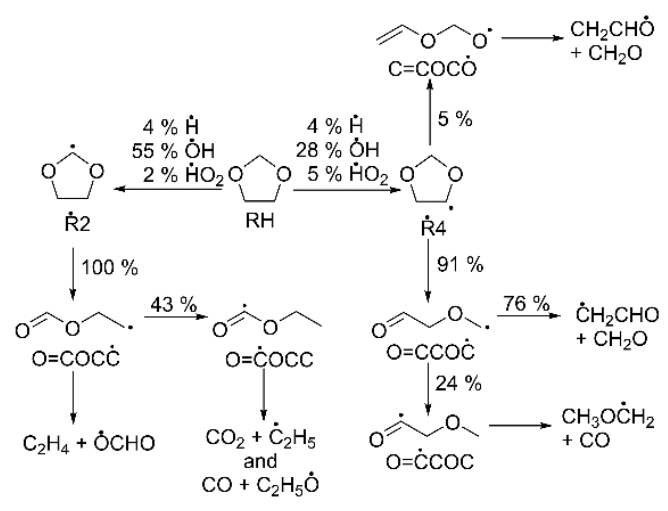

Fig. 7: Reaction pathway analysis for 1,3-dioxolane for 10 bar at $850 \mathrm{~K}$ in a JSR.

The radicals of 1,3-dioxolane decompose only via $\beta$-scission and no low temperature branching is observed. The high dilution of the reactant in nitrogen in the JSR experiments quenches the low temperature chain branching as no cool flame was observed. Ethylene and formaldehyde are mainly produced by $\beta$-scission of the radicals 1,3-dioxolan-2-yl or 1,3-dioxolan-4-yl, respectively. The experiments show that ethylene is formed approximately twice as much as formaldehyde. This is also represented by the model. The reaction pathway analysis shows that $61 \%$ of the fuel reacts to the 1,3-dioxolan-2-yl radical while $37 \%$ react to the 1,3-dioxolan$4-y l$ radical similar to the undiluted case discussed before. As the predicted mole fraction profile of ethylene and formaldehyde lay within the uncertainty bars of the experiments the formation ratio of 1,3-dioxolan-2-yl and 1,3-dioxolan-4-yl by $\mathrm{H}$-atom abstraction seems to be correct. The main reaction partner in the $\mathrm{H}$-atom abstraction is the hydroxyl radical forming water. The simulated mole fraction profile of water is in good agreement with the experimental data for temperatures under $1000 \mathrm{~K}$. A comparable behavior is observed for $\mathrm{H}_{2}$. Until $1000 \mathrm{~K}$ the mole fraction profile is within the error bars whereas at higher temperatures the amount of hydrogen is underpredicted by the model. Both water and hydrogen are mainly formed from either dioxolane or formaldehyde by $\mathrm{H}$-atom abstraction via $\dot{\mathrm{H}}$ or $\dot{\mathrm{O}}$. Formaldehyde can also react via $\mathrm{H}$-atom abstraction by $\dot{\mathrm{C}} \mathrm{H}_{3}$ forming $\mathrm{CH}_{4}$ and $\mathrm{HCO}$. This is the second most important reaction pathway leading to methane. As depicted in Fig. 6 , the peak mole fraction of methane is predicted at lower temperatures than measured experimentally. The $\dot{\mathrm{C}} \mathrm{H}_{3}$ reacting to $\mathrm{CH}_{4}$ is mainly formed by the decomposition of ethoxy radicals $\left(\mathrm{C}_{2} \mathrm{H}_{5} \mathrm{O}\right)$ to $\mathrm{CH}_{2} \mathrm{O}$ and $\dot{\mathrm{CH}}_{3}$. $\mathrm{C}_{2} \mathrm{H}_{5} \mathrm{O}$ comes from the decomposition of ethyl formyl $(\mathrm{O}=\dot{\mathrm{COCC}}$ ) to which the ethyl- 
2-yl formate $(\mathrm{O}=\mathrm{COC} \dot{\mathrm{C}})$ can isomerize. A possible reason for the discrepancy between the current model and the measured results could be that the decomposition of $\mathrm{C}_{2} \mathrm{H}_{5} \mathrm{O}$ to $\mathrm{CH}_{2} \mathrm{O}$ and $\mathrm{CH}_{3}$ is too fast and it should mainly decompose to $\mathrm{CH} 3 \mathrm{CHO}$ and $\dot{\mathrm{H}}$.

\section{Conclusion}

The ignition delay times of stoichiometric 1,3-dioxolane/ $\mathrm{O}_{2} /$ inert mixtures were measured in a rapid compression machine and shock tube at pressures of 20 and 40 bar covering a temperature range of $630 \mathrm{~K}$ to $1300 \mathrm{~K}$. Furthermore, the mole fraction profiles of the stable intermediates produced during the oxidation of 1,3-dioxolane were measured in a jet-stirred reactor for $10 \mathrm{~atm}$ at $\phi=1.0$. The most abundant stable intermediates measured during the oxidation of 1,3-dioxolane in a jet-stirred reactor are ethylene, formaldehyde, $\mathrm{CO}, \mathrm{CO}_{2}$, water and methane. In the low temperature range the influence of the low temperature chemistry is observed on the ignition delay times whereas it is not observed on the mole fraction profiles in the highly diluted conditions of the jet-stirred reactor. A detailed kinetic mechanism for the oxidation of 1,3-dioxolane was developed in this work and validated against ignition delay times and mole fraction profiles. The model showed that the 1,3-dioxolane mainly yields the two primary radicals 1,3dioxolan-2-yl and 1,3-dioxolan-4-yl, whereby the 1,3-dioxolan-2-yl radical is formed faster for all investigated conditions. This is caused by the difference in bond dissociation energies for the R2-H $(91.1 \mathrm{kcal} / \mathrm{mol})$ and R4$\mathrm{H}(92.9 \mathrm{kcal} / \mathrm{mol})$ sides. The calculated $\mathrm{C}-\mathrm{H}$-bond dissociation energies are similar to the ones from tetrahydrofuran in a position to the oxygen $(93.8 \mathrm{kcal} / \mathrm{mol}$ [28]) and dimethoxy methane $(92.9 \mathrm{kcal} / \mathrm{mol}$ [27]) at the methylene side. Comparing the low temperature chemistry behavior of the two primary radicals 1,3dioxolan-2-yl and 1,3-dioxolan-4-yl the addition on $\mathrm{O}_{2}$ is not efficient if two oxygens are in $\alpha$ position to the carbon because of the energetically hindrance of the two oxygen. Moreover, it was observed that the $\mathrm{QOOH}$ species quickly undergo a $\beta$-scission inhibiting the reaction to olefins $+\mathrm{HO}_{2}$ and cyclic ethers $+\dot{\mathrm{O}} \mathrm{H}$. This behavior differs from alkanes and explains the almost temperature independent ignition delay times in the negative temperature coefficient range.

\section{Acknowledgements}

This work at PCFC was performed as part of the Cluster of Excellence "The Fuel Science Center" (EXC 2186), which is funded by the Excellence Initiative by the German federal and state governments to promote science and research at German universities. The work in DRIVE was supported by Bourgogne Council under the PARI2 program and Labex Caprysses.

\section{References}

[1] J. Kiernan, Formaldehyde, formalin, paraformaldehyde and glutaraldehyde: what they are and what they do, Micros. Today. 12 (2000) 8-12.

[2] H. Li, C. Wu, Q. Zhang, X. Li, X. Gao, Synthesis of 1,3-Dioxolane from Aqueous Formaldehyde Solution and Ethylene Glycol: Kinetics and Reactive Distillation, Ind. Eng. Chem. Res. 58 (2019) 7025-7036.

[3] X. Wang, A.K. Beine, R. Palkovits, 1,2-Propylene Glycol and Ethylene Glycol Production from Lignocellulosic Biomass, 1st ed., Elsevier B.V., 2019.

[4] R.N. Hader, R.D. Wallace, R.W. McKinney, Formaldehyde From Methanol, Ind. Eng. Chem. 44 (1952) $1508-1518$. https://doi.org/10.1021/ie50511a016.

[5] A. Demirbas, Biomethanol production from organic waste materials, Energy Sources, Part A Recover. Util. Environ. Eff. 30 (2008) 565-572.

[6] J. Song, V. Zello, A.L. Boehman, Comparison of the Impact of Intake Oxygen Enrichment and Fuel Oxygenation on Diesel Combustion and Emissions, Energy \& Fuels. 18 (2004) 1282-1290.

[7] C.G. Sauer, I. Barnes, K.H. Becker, H. Geiger, T.J. Wallington, L.K. Christensen, J. Platz, O.J. Nielsen, Atmospheric Chemistry of 1,3-Dioxolane: Kinetic, Mechanistic, and Modeling Study of OH Radical Initiated Oxidation, J. Phys. Chem. A. 103 (1999) 5959-5966.

[8] H. Cutler, Kinetics and mechanism of the vapor phase pyrolysis of 1,3-dioxolane in steam, J. Anal. Appl. Pyrolysis. 12 (1987) 223-242.

[9] E. Fernández-Sánchez, J.A. García-Domínguez, B. de la Iglesia-Gayá, Radical-sensitized thermal decomposition of 1,3-dioxolane in the gas phase, J. Anal. Appl. Pyrolysis. 18 (1991) 219-232. 
[10] W.B. Guenther, W.D. Walters, The Thermal Decomposition of Dioxolane, J. Am. Chem. Soc. 73 (1951) 21272131.

[11] B.C. Roquitte, The photochemistry of 1,3-Dioxolane, J. Phys. Chem. 70 (1966) 2863-2868.

[12] M.J. Molera, J.A. García-Domínguez, A.U. Acuna, Gas-phase Oxidation of 1,3-Dioxolan, J. Chem. Soc. B Phys. Org. (1971) 1916-1923.

[13] H. El Merhubi, A. Kéromnès, G. Catalano, B. Lefort, L. Le Moyne, A high pressure experimental and numerical study of methane ignition, FUEL. 177 (2016) 164-172.

[14] C. Morley, GASEQ, (2005). http://www.gaseq.co.uk/.

[15] B.C. Lee, S. Vranckx, K.A. Heufer, S. V Khomik, Y. Uygun, H. Olivier, R.X. Fernandes, On the Chemical Kinetics of Ethanol Oxidation : Shock Tube, Rapid Compression Machine and Detailed Modeling Study, Z. Phys. Chem. 226 (2012) 1-27.

[16] A. Ramalingam, K. Zhang, A. Dhongde, L. Virnich, H. Sankhla, H. Curran, A. Heufer, An RCM experimental and modeling study on $\mathrm{CH} 4$ and $\mathrm{CH} 4$ / C 2 H 6 oxidation at pressures up to 160 bar, Fuel. 206 (2017) 325-333.

[17] P. Dagaut, M. Cathonnet, J.P. Rouan, R. Foulatier, A. Quilgars, J.C. Boettner, F. Gaillard, H. James, A jet-stirred reactor for kinetic studies of homogeneous gas-phase reactions at pressures up to ten atmospheres $(\sim 1 \mathrm{MPa})$, J. Phys. E. 19 (1986) 207-209.

[18] Z. Serinyel, C. Togbé, A. Zaras, G. Dayma, P. Dagaut, Kinetics of oxidation of cyclohexanone in a jet-stirred reactor: Experimental and modeling, Proc. Combust. Inst. 35 (2015) 507-514.

[19] M.J. Frisch, G.W. Trucks, H.B. Schlegel, G.E. Scuseria, J.R. Robb, G. Scalmani et al, Gaussian 09, (2016). https://gaussian.com/glossary/g09/.

[20] K.P. Somers, J.M. Simmie, Benchmarking Compound Methods (CBS-QB3, CBS-APNO, G3, G4, W1BD) against the Active Thermochemical Tables: Formation Enthalpies of Radicals, J. Phys. Chem. A. 119 (2015) 8922-8933.

[21] K. Pihlaja, J. Heikkilä, B. Beagley, T. Aalto, P.-E. Werner, U. Junggren, B. Lamm, B. Samuelsson, Enthalpies of Formation of Cyclic Acetals. 1,3-Dioxolane, 2-Methyl-1,3-Dioxolane, and 2,4-Dimethyl-1,3-Dioxolanes., Acta Chem. Scand. 23 (1969) 1053-1055.

[22] U. Burke, J. Beeckmann, W.A. Kopp, Y. Uygun, H. Olivier, K. Leonhard, H. Pitsch, K.A. Heufer, A comprehensive experimental and kinetic modeling study of butanone, 168 (2016) 296-309.

[23] Y. Georgievskii, J.A. Miller, M.P. Burke, S.J. Klippenstein, Reformulation and solution of the master equation for multiple-well chemical reactions, J. Phys. Chem. A. 117 (2013) 12146-12154.

[24] M. Döntgen, K. Leonhard, Reactions of Chemically Activated Formic Acid Formed via HCO + OH, J. Phys. Chem. A. 120 (2016) 1819-1824.

[25] B. Xu, J. Garrec, A. Nicolle, M. Matrat, L. Catoire, Temperature and Pressure Dependent Rate Coefficients for the Reaction of Ketene with Hydroxyl Radical, J. Phys. Chem. A. 123 (2019) 2483-2496.

[26] C.W. Gao, J.W. Allen, W.H. Green, R.H. West, Reaction Mechanism Generator: Automatic construction of chemical kinetic mechanisms, Comput. Phys. Commun. 203 (2016) 212-225.

[27] Y.-R. Luo, Handbook of bond dissociation energies in organic compounds, CRC Press, 2003.

[28] Y. Fenard, A. Gil, G. Vanhove, H. Carstensen, K.M. Van, P.R. Westmoreland, O. Herbinet, F. Battin-leclerc, A model of tetrahydrofuran low-temperature oxidation based on theoretically calculated rate constants, Combust. Flame. 191 (2018) 252-269.

[29] C.-W. Zhou, Y. Li, U. Burke, C. Banyon, K.P. Somers, S. Khan, J.W. Hargis, T. Sikes, E.L. Petersen, M. AlAbbad, A. Farooq, Y. Pan, Y. Zhang, Z. Huang, J. Lopez, Z. Loparo, S.S. Vasu, H.J. Curran, An experimental and chemical kinetic modeling study of 1,3-butadiene combustion: Ignition delay time and laminar flame speed measurements, Combust. Flame. 197 (2018) 423-438.

[30] H.J. Curran, P. Gaffuri, W.J. Pitz, C.K. Westbrook, A Comprehensive Modeling Study of n-Heptane Oxidation, Combust. Flame. 114 (1998) 149-177.

[31] R. De Bruycker, L. Tran, H. Carstensen, P. Glaude, F. Monge, M.U. Alzueta, F. Battin-leclerc, K.M. Van Geem, Experimental and modeling study of the pyrolysis and combustion of 2-methyl-tetrahydrofuran, Combust. Flame. 176 (2017) 409-428.

[32] L.C. Kröger, M. Döntgen, D. Firaha, W.A. Kopp, K. Leonhard, Ab initio kinetics predictions for H-atom abstraction from diethoxymethane by hydrogen, methyl, and ethyl radicals and the subsequent unimolecular reactions, Proc. Combust. Inst. 37 (2019) 275-282.

[33] P. Dagaut, R. Liu, T.J. Wallington, M.J. Kurylo, Flash photolysis resonance fluorescence investigation of the gasphase reactions of hydroxyl radicals with cyclic ethers, J. Phys. Chem. 94 (1990) 1881-1883.

[34] J. Mendes, C.W. Zhou, H.J. Curran, Rate constant calculations of H-atom abstraction reactions from ethers by HÓ 2 radicals, J. Phys. Chem. A. 118 (2014) 1300-1308.

[35] S. Jacobs, M. Döntgen, A.B.S. Alquaity, W.A. Kopp, C. Leif, U. Burke, H. Pitsch, K. Leonhard, H.J. Curran, K. Alexander, Detailed kinetic modeling of dimethoxymethane. Part II : Experimental and theoretical study of the 
kinetics and reaction mechanism, Combust. Flame. 205 (2019) 522-533.

[36] K. Zhang, C. Banyon, J. Bugler, H.J. Curran, A. Rodriguez, O. Herbinet, F. Battin-leclerc, C.B. Chir, K. Alexander, An updated experimental and kinetic modeling study of $n$ - heptane oxidation, Combust. Flame. 172 (2016) 116135.

[37] D.G. Goodwin, H.K. Moffat, R.L. Speth, Cantera: An Object-oriented Software Toolkit for Chemical Kinetics, Thermodynamics, and Transport Processes, (2017).

[38] C.J. Sung, H.J. Curran, Using rapid compression machines for chemical kinetics studies, Prog. Energy Combust. Sci. 44 (2014) 1-18.

[39] F. Battin-Leclerc, Detailed chemical kinetic models for the low-temperature combustion of hydrocarbons with application to gasoline and diesel fuel surrogates, Prog. Energy Combust. Sci. 34 (2008) 440-498.

[40] J. Bugler, B. Marks, O. Mathieu, R. Archuleta, A. Camou, C. Grégoire, K.A. Heufer, E.L. Petersen, H.J. Curran, An ignition delay time and chemical kinetic modeling study of the pentane isomers, 163 (2016) 138-156. 